\title{
Development Trend Analysis on Corn Futures Price in Our Country by Multiple Regression Model
}

\author{
Chen Junyi \\ Business School \\ Huaihai Institute of Technology \\ Lianyungang, 222005, China \\ xizf98@126.com
}

\author{
Pingyuan Xi \\ School of Mechanical Engineering \\ Huaihai Institute of Technology \\ Lianyungang, 222005, China \\ xipingy@hhit.edu.cn
}

\begin{abstract}
As the main influence factors on price fluctuations of corn futures is more complex, so analyzing these factors that is very difficult. In this paper, China's consumer confidence index and consumer price index are selected as variables of the rational expectations so that the econometric model is created in multiple regression by EViews software. Finally, this paper forecasts the future developing trend of corn futures price, and it would have certain theoretical meaning and realistic significance.
\end{abstract}

Keywords- corn futures price; development trend; multiple regression model

\section{INTRODUCTION}

There is great corn yield in our country, and the domestic corn consumption mostly depended on local supply. But the futures market is an open market, therefore the domestic and international market closely linked together, and the foreign market changes, especially the United States CBOT corn market, could greatly affect price changes of corn futures contract of the Dalian DCE futures market in our country. According to the former research achievements, the Dalian DCE corn futures price trend is overall consistent with the United States CBOT corn futures price, and sometimes the DCE corn futures price change before the CBOT corn futures price, it shows that corn futures price trend has the certain independence.With our country corn futures market development gradually mature, the price discovery function is more and more remarkable [1].

At present the global economy is on recovery phase, and uncertainty factors determine that the probability of economic development fluctuation is very great. Strengthening the research of the variable factors of corn futures price, could better grasp the corn futures price trend, is helpful to avoid risk through hedging for corn farmers and related enterprises, and is beneficial to stabilizing corn production and food prices, so as to promote price running smoothly. As the main influence factors on price fluctuations of corn futures is more complex, so analyzing these factors that is very difficult. Therefore, it would have certain theoretical meaning and realistic significance to analyze changes factors of China's corn futures price by multiple regression model and forecast the future trend of corn futures price combining with the demonstration results [2].

\section{Multiple Regression AnAlysis ON CHANGING FACTORS OF CORN FUTURES PRICE}

\section{A. Main Influence Factors of Corn Futures Price in Our Country}

There are many influence factors in corn futures prices, such as the supply and demand of corn, climatic conditions, economic cycle, currency exchange rate and the relevant state policies etc.. The supply and demand situation of corn includes the supply and demand of corn, corn stock and the price of related products. In international corn market, the corn yield of the United States has become the most important factors of influencing international corn supply.Compared with soybean and other agricultural products, corn production in our country has relative independence, so every year domestic corn yield become the main factors of influencing the domestic corn supply. The United States, China, the European Union, Japan and Brazil are the main consumers, and these countries consumer demand could greatly influence the corn price changes. And merchandise inventory level is the inner reflection to the pattern of commodity supply and demand, so the corn inventory status could also impact for the corn price. As agricultural products, corn prices would also be affected by the climate. In addition, economic cycle is a inevitable economic fluctuation in the modern economic society.So from the macro aspect, the economic cycle is also one of the very important influencing factors. As our country corn futures price is weighed by the RMB currency, the fluctuation of exchange rate would inevitably affect on corn futures prices. At last, China's relevant policies would greatly influence on corn market and price trend [3].

\section{B. Selecting Explanatory Variables}

According to the cost theory, the spot price is the decisive factor of futures price. It can be seen that the discovery function of corn futures price has been very significant, so corn spot price is no longer selected as explanatory variables in this paper. In addition, the interest rate impacts on holding costs and storage costs of the traders. And there is a strong correlation between the money supply and interest rate, so the money supply (M2) is taken into consideration as a factors. In addition, the changes in the exchange rate could also affect the holding costs and storage costs of corn futures traders, therefore currency exchange rate is selected as a explanatory 
variables. Therefore, in this article China's consumer confidence index and consumer price index are selected as variables of the rational expectations [4].

\section{Creating Econometric Model}

Through the financial crisis from 2007 to 2008, the global economy had begun to gradually recovery. As this paper researches mainly the corn futures market at recovery phase, so sample interval is from January 2009 to December 2011, the sample data as shown in Table 1. The explanatory variables as follows:

$Y$ - corn futures price, according to relevant data in DCE,

$X_{2}$ - soybean futures price, according to relevant data in DCE,

$X_{3}$ - exchange rate,

$X_{4}$-money supply, (hundred million yuan),

$X_{5}$-consumer confidence index,

$X_{6}$-consumer prices index.

The mean value of clearing price of all corn futures contracts in DCE at the end of a month is selected as the value of corn futures price, likewise, soybean futures price is calculated, and China's currency and Quasi-money as value of money supply, so the econometric model created is as follows:

The establishment of the econometric model are as follows:

$$
\begin{aligned}
\mathrm{Y}_{t}= & \beta_{1}+\beta_{2} X_{2 t}+\beta_{3} X_{3 t}+\beta_{4} X_{4 t}+\beta_{5} X_{5 t} \\
& +\beta_{6} X_{6 t}+\mu_{t}
\end{aligned}
$$

Where $\beta_{\mathrm{i}}(\mathrm{i}=1,2,3,4,5,6)$ is regression coefficient [5].

\section{Multiple REgRESSION ANALYSIS}

The econometric model with above data is solved in regression analysis by Eviews software, the output as shown in Table 2. follows:

$$
\begin{aligned}
\hat{Y}_{\mathrm{t}}= & 7662.221-0.002 X_{2 \mathrm{t}}-1251.377 X_{3 \mathrm{t}}+0.001 X_{4 \mathrm{t}} \\
& +3.467 X_{5 \mathrm{t}}+14.613 X_{6 \mathrm{t}} \\
R^{2}= & 0.9856, \overline{R^{2}}=0.9820, F=273.0828, d f=20 \quad[6] .
\end{aligned}
$$

\section{A. Heteroscedastic Test}

The heteroscedastic test results of econometric model as shown in Table 2.
From Table 2 it can be seen that $n R^{2}=17.48584$, and when $\alpha=0.01$, critical value is $\chi_{0.05}^{2}(9)=21.6660$, according to distribution table of variance. As $n R^{2}=17.48584<\chi_{0.05}^{2}(9)=21.6660$, so alternative hypothesis is refused and the null hypothesis is adopted, it indicates that the econometric model does not exist heteroscedasticity [6].

\section{B. Autocorrelation Test}

The regression coefficients in the equation were significantly. For the model with 26 sample sizes and 3 explanatory variables, when level of significance was $1 \%$, by DW statistical table look-up, it can be known that $\mathrm{d}_{L}=$ 0.928, $\mathrm{d}_{U}=1.411$. And as $\mathrm{d}_{U}<\mathrm{DW}=2.0056<4-\mathrm{d}_{U}$, apparently there is no heteroscedasticity or autocorrelation in this model [7][8].

\section{PREDICTION ON DEVELOPMENT TREND OF CORN FUTURES PRICES IN CHINA}

The regression results indicated that the following conclusion: corn futures price is positive related with money supply and the consumer price index, whose related coefficient are 0.9540 and 0.9176 respectly, it also shows that the interest rate would impact greatly on corn futures prices. Furthermore regression results show that the influence of soybean futures and consumer confidence index to the corn futures is not significant. The return can conform with the theory [9].

In the long term, the international corn market price, as the market is undersupplying, corn demand is amplifying and the prices of peripheral commodity is rising, continues to go up accompanied with last year's rising trend.Along with the global economic recovery, in our country the development of corn deep processing industry is very quick, and corn demand increased rapidly, this also lay the foundation for increase of corn demand. Soybean prices, as related products of corn, remains high all the time, that also provides support for corn prices. About exchange rate, from China's current economic fundamental situation, in the stable economic growth target, it is predicted that appreciation of the RMB would keep smooth, which would slow down the long-term trend of rising of corn futures price, but the impact would not be great. Concerning for interest rates, as this year policy focus of Chinese government is to curb inflation and stabilize prices, so corn prices would face the pressure from policy. In conclusion, the long-term trends of corn futures would still mainly be upward fluctuation with stable rising [10].

\section{CONCLUSION}

This paper analyzes changes factors of China's corn futures price, and according to the rational expectations theory, China's consumer confidence index and consumer price index are selected as variables of the rational expectations. So the econometric model is created in multiple regression by EViews software. Finally, this paper forecasts the future developing trend of corn futures price. 


\section{REFERENCES}

[1] Y.J. Wen, Y.X. Wu. Empirical Study on Discovery Function Corn Futures Price in Our country. Price theory and practice, 2010 .12, p.5859.

[2] C. Xu. developing trend judgment and multiple regression analysis on changing factors of China's soybean futures price, Chinese price, 2010.6, p.30-33.

[3] XiaoYu Liu, Jun Wang. Research on international relevance of The corn futures marke between China and the U.S.A.: the empirical analysis based on the day data. Journal of the central university of finance and economics, 2009.5, p.37-42.

[4] ChenYuSheng, ZhaoRong. analysis on fluctuation reason of China's corn price, Chinese price, 2009.2, p.25-28.

[5] Bai, Z. D. ; Radhakrishna Rao, C. ; Wu, Y. M-estimation of multivariate linear regression parameters under a convex discrepancy function. Statistica Sinica, 1992.2, pp. 237-254
[6] Hannu Oja. Multivariate Nonparametric Methods with R. Lecture Notes in Statistics, 2010, Volume 199, pp.183-200

[7] Ming Yuan, Ali Ekici, Zhaosong Lu. Dimension reduction and coefficient estimation in multivariate linear regression. Journal of the Royal Statistical Society: Series B (Statistical Methodology). Volume 69, Issue 3, pages 329-346, June 2007

[8] J. D. JOBSON. A Multivariate Linear Regression Test for the Arbitrage Pricing Theory. The Journal of Finance. Volume 37, Issue 4, pages 1037-1042, September 1982

[9] Leo Breiman, Jerome H. Friedman. Predicting Multivariate Responses in Multiple Linear Regression. Journal of the Royal Statistical Society: Series B (Statistical Methodology). Volume 59, Issue1, pages 3-54, 1997

[10] A.Gao, W.J. Fan. multiple regression analysis of soybean futures price in Our country, Chinese price, 2008,6, p.10-13.

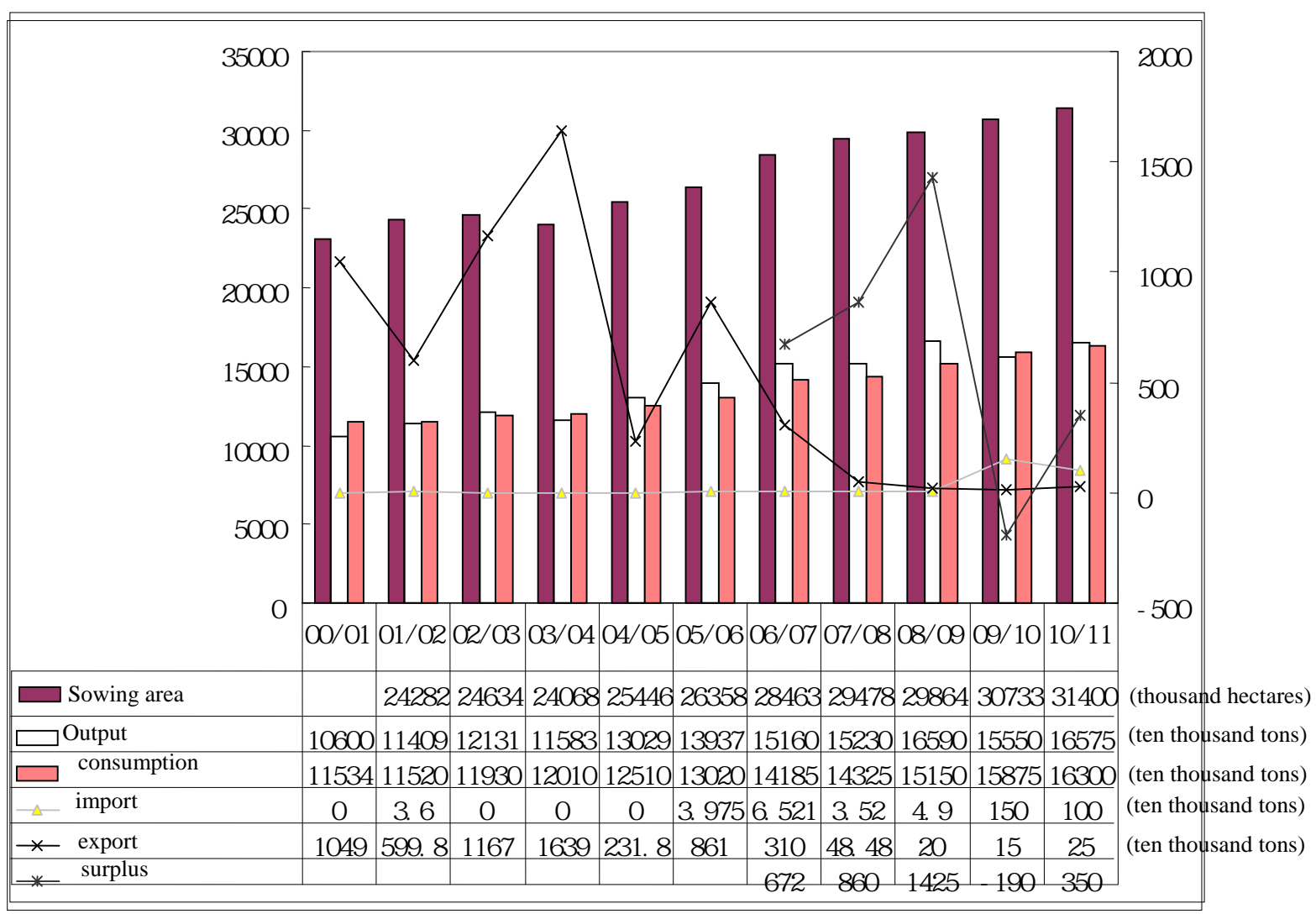

Figure 1. Balance sheet of corn supply and demand in China in 2000-2011 
TABLE I. SAMBLE DATA

\begin{tabular}{|c|c|c|c|c|c|c|}
\hline & $\begin{array}{c}Y \\
\text { Yuan/ton }\end{array}$ & 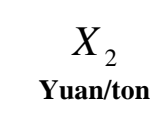 & $X_{3}$ & $\begin{array}{c}X_{4} \\
\text { hundred } \\
\text { million yuan }\end{array}$ & $X_{5}$ & $X_{6}$ \\
\hline 2009.01 & 1,572 & 2,734 & 6.8382 & 496135.31 & 101.3 & 101.0 \\
\hline 2009.02 & 1,612 & 2,488 & 6.8357 & 506708.07 & 101.0 & 98.4 \\
\hline 2009.03 & 1,653 & 2,704 & 6.8341 & 530626.71 & 100.3 & 98.8 \\
\hline 2009.04 & 1,656 & 2,705 & 6.8312 & 540481.21 & 100.5 & 98.5 \\
\hline 2009.05 & 1,652 & 2,923 & 6.8245 & 548263.51 & 101.2 & 98.6 \\
\hline 2009.06 & 1,636 & 3,024 & 6.8332 & 568916.20 & 101.0 & 98.3 \\
\hline 2009.07 & 1,642 & 3,018 & 6.8320 & 573102.85 & 102.1 & 98.2 \\
\hline 2009.08 & 1,733 & 3,072 & 6.8322 & 576698.95 & 102.7 & 98.8 \\
\hline 2009.09 & 1,720 & 2,914 & 6.8289 & 585405.34 & 102.8 & 99.2 \\
\hline 2009.10 & 1,726 & 2,994 & 6.8275 & 586643.29 & 103.2 & 99.5 \\
\hline 2009.11 & 1,775 & 3,195 & 6.8274 & 594604.72 & 103.3 & 100.6 \\
\hline 2009.12 & 1,828 & 3,165 & 6.8279 & 610224.52 & 103.9 & 101.9 \\
\hline 2010.01 & 1,823 & 2,917 & 6.8273 & 625609.29 & 104.7 & 101.5 \\
\hline 2010.02 & 1,832 & 2,857 & 6.8270 & 636072.26 & 104.2 & 102.7 \\
\hline 2010.03 & 1,894 & 2,882 & 6.8264 & 649947.46 & 107.9 & 102.4 \\
\hline 2010.04 & 1,908 & 2,943 & 6.8262 & 656561.22 & 106.6 & 102.8 \\
\hline 2010.05 & 1,933 & 2,816 & 6.8274 & 663351.37 & 108.0 & 103.1 \\
\hline 2010.06 & 1,882 & 2,796 & 6.8165 & 673921.72 & 108.5 & 102.9 \\
\hline 2010.07 & 1,971 & 2,968 & 6.7775 & 674051.48 & 107.8 & 103.3 \\
\hline 2010.08 & 2,000 & 3,056 & 6.7901 & 687506.92 & 107.3 & 103.5 \\
\hline 2010.09 & 2,044 & 3,282 & 6.7462 & 696471.50 & 104.1 & 103.6 \\
\hline 2010.10 & 2,167 & 3,343 & 6.6732 & 699776.74 & 103.8 & 104.4 \\
\hline 2010.11 & 2,177 & 3,203 & 6.6558 & 710339.03 & 102.9 & 105.1 \\
\hline 2010.12 & 2,203 & 3,358 & 6.6515 & 725851.79 & 100.4 & 104.6 \\
\hline 2011.01 & 2,242 & 3,410 & 6.6027 & 733884.83 & 99.9 & 104.9 \\
\hline 2011.02 & 2,355 & 3,359 & 6.5831 & 736130.86 & 99.6 & 104.9 \\
\hline
\end{tabular}

TABLE II. REGRESSION ANALYSIS OUTPUT

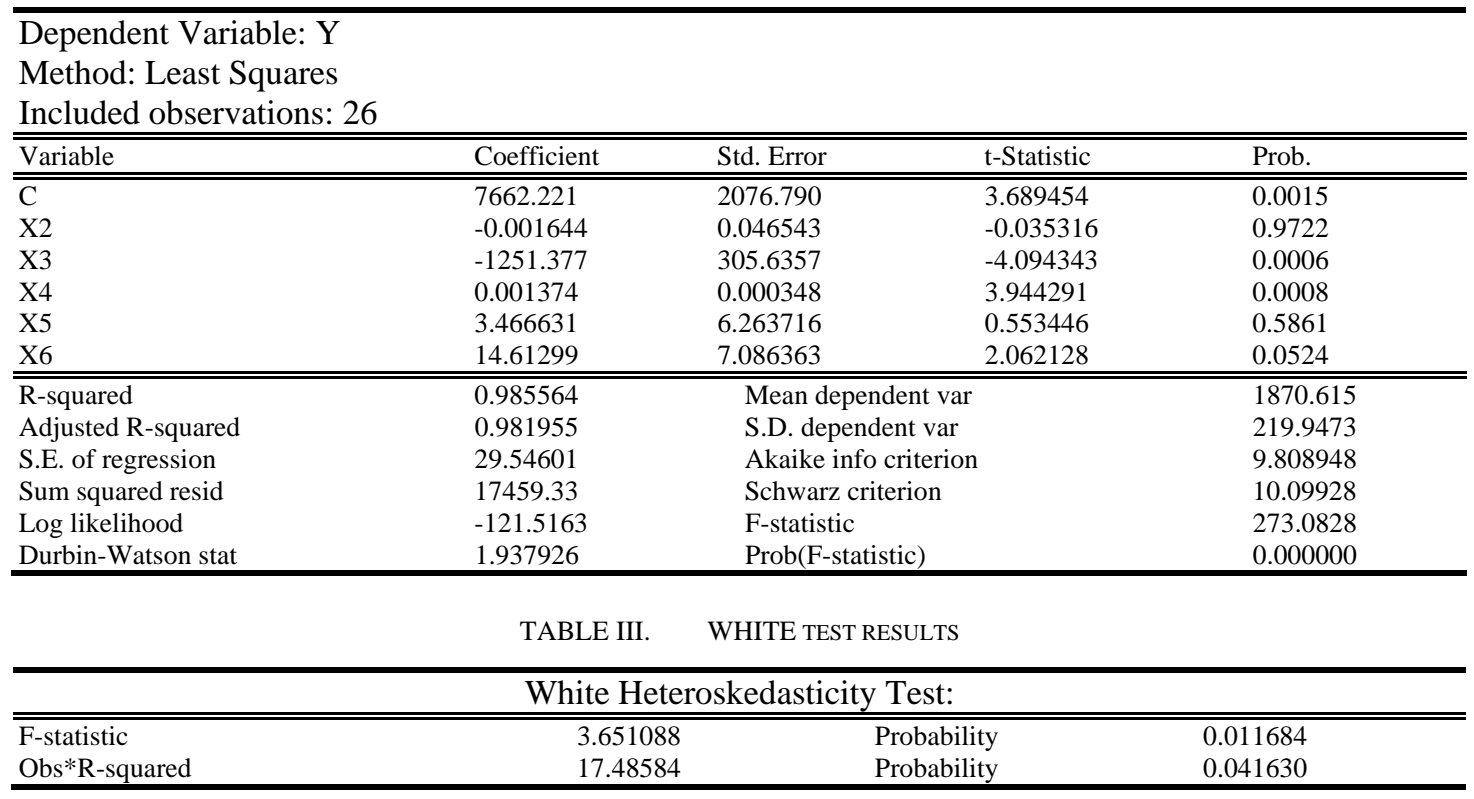

